\title{
Novel carfilzomib-based combinations as potential therapeutic strategies for liposarcomas
}

\author{
Maya Jeitany ${ }^{1,2}$ (D) Aishvaryaa Prabhu ${ }^{1} \cdot$ Pushkar Dakle $^{1} \cdot$ Elina Pathak $^{1,3} \cdot$ Vikas Madan $^{1} \cdot$ Deepika Kanojia $^{1}$. \\ Vineeth Mukundan ${ }^{1} \cdot$ Yan Yi Jiang ${ }^{1} \cdot$ Yosef Landesman $^{4} \cdot$ Wai Leong Tam $^{1,3} \cdot$ Dennis Kappei $^{1,5}{ }^{(0)}$. \\ H. Phillip Koeffler ${ }^{1,6,7}$
}

Received: 5 May 2020 / Revised: 19 July 2020 / Accepted: 7 August 2020 / Published online: 26 August 2020

(c) The Author(s) 2020

\begin{abstract}
Proteasome inhibitors, such as bortezomib and carfilzomib, have shown efficacy in anti-cancer therapy in hematological diseases but not in solid cancers. Here, we found that liposarcomas (LPS) are susceptible to proteasome inhibition, and identified drugs that synergize with carfilzomib, such as selinexor, an inhibitor of XPO1-mediated nuclear export. Through quantitative nuclear protein profiling and phospho-kinase arrays, we identified potential mode of actions of this combination, including interference with ribosome biogenesis and inhibition of pro-survival kinase PRAS40. Furthermore, by assessing global protein levels changes, FADS2, a key enzyme regulating fatty acids synthesis, was found down-regulated after proteasome inhibition. Interestingly, SC26196, an inhibitor of FADS2, synergized with carfilzomib. Finally, to identify further combinational options, we performed high-throughput drug screening and uncovered novel drug interactions with carfilzomib. For instance, cyclosporin A, a known immunosuppressive agent, enhanced carfilzomib's efficacy in vitro and in vivo. Altogether, these results demonstrate that carfilzomib and its combinations could be repurposed for LPS clinical management.
\end{abstract}

Keywords Proteasome inhibitors $\cdot$ Liposarcoma $\cdot$ Combinational therapies

Electronic supplementary material The online version of this article (https://doi.org/10.1007/s00018-020-03620-w) contains supplementary material, which is available to authorized users.

Maya Jeitany

maya.jeitany@gmail.com

1 Cancer Science Institute of Singapore, National University of Singapore, Singapore, Singapore

2 School of Biological Sciences, Nanyang Technological University, Singapore, Singapore

3 Genome Institute of Singapore, Agency for Science, Technology and Research (A*STAR), Singapore, Singapore

4 Karyopharm Therapeutics, Newton, MA, USA

5 Department of Biochemistry, Yong Loo Lin School of Medicine, National University of Singapore, Singapore, Singapore

6 Cedars-Sinai Medical Center, Division of Hematology/Oncology, UCLA School of Medicine, Los Angeles, CA, USA

7 Department of Hematology-Oncology, National University Cancer Institute of Singapore (NCIS), National University Hospital, Singapore, Singapore

\section{Introduction}

The ubiquitin-proteasome system (UPS) is a component that precisely controls the turnover of the majority of proteins [1], making it a critical regulator of numerous cellular pathways. Proper degradation of either misfolded or damaged proteins requires the concerted action of ubiquitin ligases and deubiquitinating enzymes, as well as the proteasome, a multi-subunit complex with proteolytic function. Several pharmacological agents have been developed to target the UPS, including bortezomib and carfilzomib, which inhibit the $20 \mathrm{~S}$ catalytic core of the proteasome. While these two drugs inhibit the same target, they are structurally distinct. Carfilzomib binds irreversibly to the proteasome, thus sustaining a prolonged inhibition [2]. In addition, carfilzomib shows less peripheral neuropathy in patients [3].

Most cells express the constitutive proteasome, while hematopoietic cells express the immunoproteasome. The active subunits of constitutive proteasomes are $\beta 5 \mathrm{c}$ (PSMB5), $\beta 1 \mathrm{c}$ (PSMB6) and $\beta 2 \mathrm{c}$ (PSMB7) while immunoproteasomes contain instead $\beta 5$ i (PSMB8), $\beta 1$ i (PSMB9) and $\beta 2 \mathrm{i}$ (PSMB10) subunits [4]. Carfilzomib and bortezomib 
can target both types of proteasomes by inhibiting the $\beta 5 \mathrm{c}$ and $\beta 5$ i subunits [5].

Proteasome inhibitors demonstrated to be highly efficient in a number of hematologic malignancies. For instance, bortezomib and carfilzomib are used as one of the standard treatments for multiple myeloma (MM) and relapsed/refractory MM, respectively $[6,7]$. However, the efficacy of these drugs as single agents in solid cancers is still debated [8].

Soft tissue sarcomas (STS) are the most frequent type of sarcomas. Liposarcomas (LPS), arising from connective tissues, are the most frequent subtype of STS [9] and can be classified into well-differentiated LPS, dedifferentiated LPS, myxoid/round cell LPS and pleomorphic LPS [10]. While localized tumors can be treated by surgical resection, metastatic or unresectable tumors poorly respond to chemotherapy [11]. Therefore, new therapeutic strategies effective for all subtypes are needed.

In this study, we assess the use of carfilzomib in LPS, as a mono-therapy or in combination with other compounds. We show that carfilzomib alone is sufficient to reduce the viability of LPS cells and the tumor burden of LPS xenograft model. To potentiate carfilzomib's efficacy, we investigated the use of an inhibitor of XPO1-mediated nuclear export, selinexor, recently described to enhance carfilzomib's efficacy [12]. To identify further effective drug combinations, we comprehensively profiled changes in the proteomic landscape after proteasome inhibition. Based on these changes, we demonstrate that combining carfilzomib with an inhibitor of FADS2 synergistically reduces the viability of LPS cells. Furthermore, subsequent drug library screening identified novel synergistic carfilzomib-based drug combinations.

\section{Materials and methods}

\section{Gene expression analyses}

Gene expression data was obtained from the CCLE database [13] (v. 20180929) in TPM units. Cell lines with missing 'Site_Primary' annotations were excluded from the analysis.

TPM values for GTex [14] and TCGA [15] samples were obtained from UCSC Toil RNAseq Recompute Compendium [16] which reanalyses all samples using a uniform analysis pipeline. Samples of the tissue type 'Adipose-Subcutaneous' were included for GTex whereas samples having 'liposarcoma' in the histologic_diagnosis were kept for TCGA.

\section{Cell culture}

Liposarcoma cell lines were cultured in RPMI medium supplemented with $10 \%$ fetal bovine serum and $1 \%$ of Penicillin and Streptomycin. Human adipose-derived stem cells (ASC) were maintained in stromal medium (LaCell). All cell lines were mycoplasma-negative. Source of cell lines, viability and clonogenic assays, generation of shRNA cells, SILAC labeling as well as used drugs are detailed in supplementary data.

\section{In vivo experiments}

Either $0.5,0.7$ or $1 \times 10^{6}$ LPS14 1 cells were inoculated subcutaneously in the flank of 6-8 weeks old NSG (NODSCID gamma) mice. DMSO (vehicle control) or carfilzomib diluted in Citrate buffer $(25 \mathrm{mM}, \mathrm{pH}=4)+10 \%$ Captisol (MedchemExpress) were administered by intraperitoneal injection on alternate days. For combinational treatments, cyclosporin A diluted in 10\% DMSO and olive oil was administered by oral gavage on alternate days. At the end of each experiment, mice were sacrificed; tumors were collected and weighed. All experiments were performed in compliance with ethical regulations of Institutional Animal Care and Use Committee (IACUC) of National University of Singapore.

\section{Proteomic studies}

For drug combination study, SILAC labeled cells were treated for $24 \mathrm{~h}$ with selinexor $(60 \mathrm{nM})$ and carfilzomib $(15 \mathrm{nM})$ and nuclear proteins were extracted using Nuclear and Cytoplasmic Protein Extraction Kit (Chongqing Bioseps). For PI-induced proteome changes studies, labeled cells were treated with carfilzomib $(80 \mathrm{nM})$ or bortezomib $(40 \mathrm{nM})$ and proteins were extracted with RIPA buffer (Thermo Fisher Scientific). Details of MS sample preparation and data acquisition, and western blot analysis are provided in supplementary data.

\section{Phospho-kinase array}

MLS402 cells were treated with either carfilzomib, selinexor or combination of both for $24 \mathrm{~h} .600 \mu \mathrm{g}$ of protein extracts were used to perform kinase phosphorylation profiling using Proteome Profiler Human Phospho-Kinase Array Kit (R\&D System, ARY003B) according to the manual's instructions.

\section{Drug library screening}

Around 750 LPS141 cells were plated in 384-well plates. The following day, 317 drugs from the Selleckchem anticancer compound library were added using Agilent Bravo Automated Liquid Handling Platform (Agilent) at a final concentration of $1 \mu \mathrm{M}$, in addition to DMSO for 3 plates and carfilzomib at $7.5 \mathrm{nM}$ or $15 \mathrm{nM}$ for 2 plates each. 3 days post-treatment, CellTiter-Glo ${ }^{\circledR}$ reagent (Promega) was added using a MultiFlo Microplate Dispenser (BioTek), 
and luminescence was measured with an Infinite M1000 Pro Microplate Reader (Tecan).

\section{Results}

\section{PSMB5 is over-expressed in soft tissue sarcomas and is associated with a poor clinical outcome}

Using CCLE (Cancer Cell Line Encyclopedia) database, we analyzed mRNA levels of the constitutive proteasome and immunoproteasome across available cancer cell lines. In comparison to other cancer types, STS showed high expression of PSMB5, PSMB6 and PSMB7, the subunits of the constitutive proteasome and low levels of PSMB8, PSMB9 and PSMB10, the subunits specific to immunoproteasomes (Fig. 1a).

Moreover, PSMB5, the target of bortezomib and carfilzomib, was found overexpressed in liposarcoma patient samples in comparison to normal adipose tissue (Fig. 1b). Furthermore, survival analysis of sarcomas patients, including liposarcoma patients, revealed that a higher expression of PSMB5 mRNA correlates with a poorer clinical outcome (Fig. 1c).

We then examined the sensitivity of cancer cell lines to bortezomib in the Cancer Therapeutics Response Portal (CTRP; http://www.broadinstitute.org/ctrp). CTRP data-

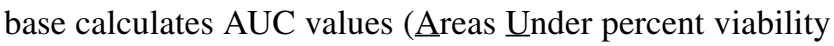
Curves) which reflects levels of inhibition across all cancer cell lines [17]. Soft tissue cancers exhibited a better response to bortezomib compared to most solid cancers (Fig. 1d). In addition, we recently assessed the effects of 120 drugs on the viability of liposarcoma cell lines covering the major subtypes of LPS [18]. In the presence of bortezomib, reduced viability was seen across all subtypes.

Taken together, these observations indicate a dependency of STS, especially liposarcomas, to the UPS, which prompted us to investigate the efficacy of proteasome inhibitors in LPS.

\section{Carfilzomib reduces the viability of LPS cells in vitro and in vivo}

Sensitivity of different subtypes of LPS cells to bortezomib and carfilzomib was verified in viability assays (Fig. 2a). All cell lines showed reduced viability after 3 days of treatment. Every half-maximal inhibitory concentration (IC50) was in the nanomolar range $(<10 \mathrm{nM})$ (Fig. 2b), while normal adipose-derived stem cells (ASCs) had an IC50 higher than $250 \mathrm{nM}$ for carfilzomib and higher than $20 \mathrm{nM}$ for bortezomib (Supplementary Figure S1a). The anti-cancer effect of bortezomib and carfilzomib was confirmed by clonogenic assays on LPS141 (dedifferentiated LPS) and MLS402 (myxoid LPS) cells (Fig. 2c, d). Carfilzomib exhibited a better efficacy than bortezomib in reducing colony-forming ability, even at concentrations lower than $3 \mathrm{nM}$ (Supplementary Figure S1b). We, therefore, chose carfilzomib for further testing in vivo. To that end, LPS 141 cells were injected sub-cutaneously in immunocompromised mice. 4 to 5 days following injection, either carfilzomib or vehicle control were administered via intraperitoneal route on alternate days (Fig. 2e-g). In a dose-dependent manner, carfilzomib reduced the growth of some LPS141 xenograft tumors (Fig. 2e-g). Mice tolerated the higher concentrations of carfilzomib since a significant change in body weight was not evident (Supplementary Figures S1c, d). These results demonstrate the potential preclinical efficacy of carfilzomib in LPS.

\section{Selinexor potentiates the effects of carfilzomib in LPS}

While carfilzomib significantly reduced tumor mass in vivo, tumors were still detected in treated mice. We thus aimed to improve the treatment efficacy through drug combination approaches. Recent studies described a synergy between carfilzomib and selinexor, an inhibitor of XPO1-mediated nuclear export, especially in MM [19-21]. Nair and colleagues also reported that pre-treating sarcoma cells with carfilzomib sensitized the cells to selinexor [12]. In addition, we have previously shown the potency of selinexor against LPS [22]. Therefore, we assessed whether a concomitant treatment of carfilzomib and selinexor can synergistically inhibit LPS viability. Combining both drugs resulted in additive effects at low concentrations and synergy at higher concentrations of selinexor, especially in MLS402 cells (Fig. 3a; Supplementary Figure S2a). A better synergy was noted in colony formation assays where a combination of low doses of each drug was sufficient to inhibit the clonogenic capacity of both cell lines (Fig. 3b; Supplementary Figure S2b).

To delineate cellular changes following both proteasome and XPO1-mediated nuclear export inhibition, we evaluated nuclear protein expression profiles of MLS402 cells by SILAC-based quantitative mass spectrometry, using drug concentrations that exhibited synergy in viability assays. Analysis of accumulated proteins in nuclear fractions has previously shown to be a useful approach for the identification of nuclear export targets of XPO1 [23]. Labeled MLS402 cells (Heavy $(\mathrm{H})$ or Light $(\mathrm{L})$ ) were treated for $24 \mathrm{~h}$ with either selinexor $(60 \mathrm{nM})$, carfilzomib $(15 \mathrm{nM})$, or both drugs, and nuclear proteins were extracted and subjected to LC-MS/MS analysis (Fig. 3c). For each condition, 

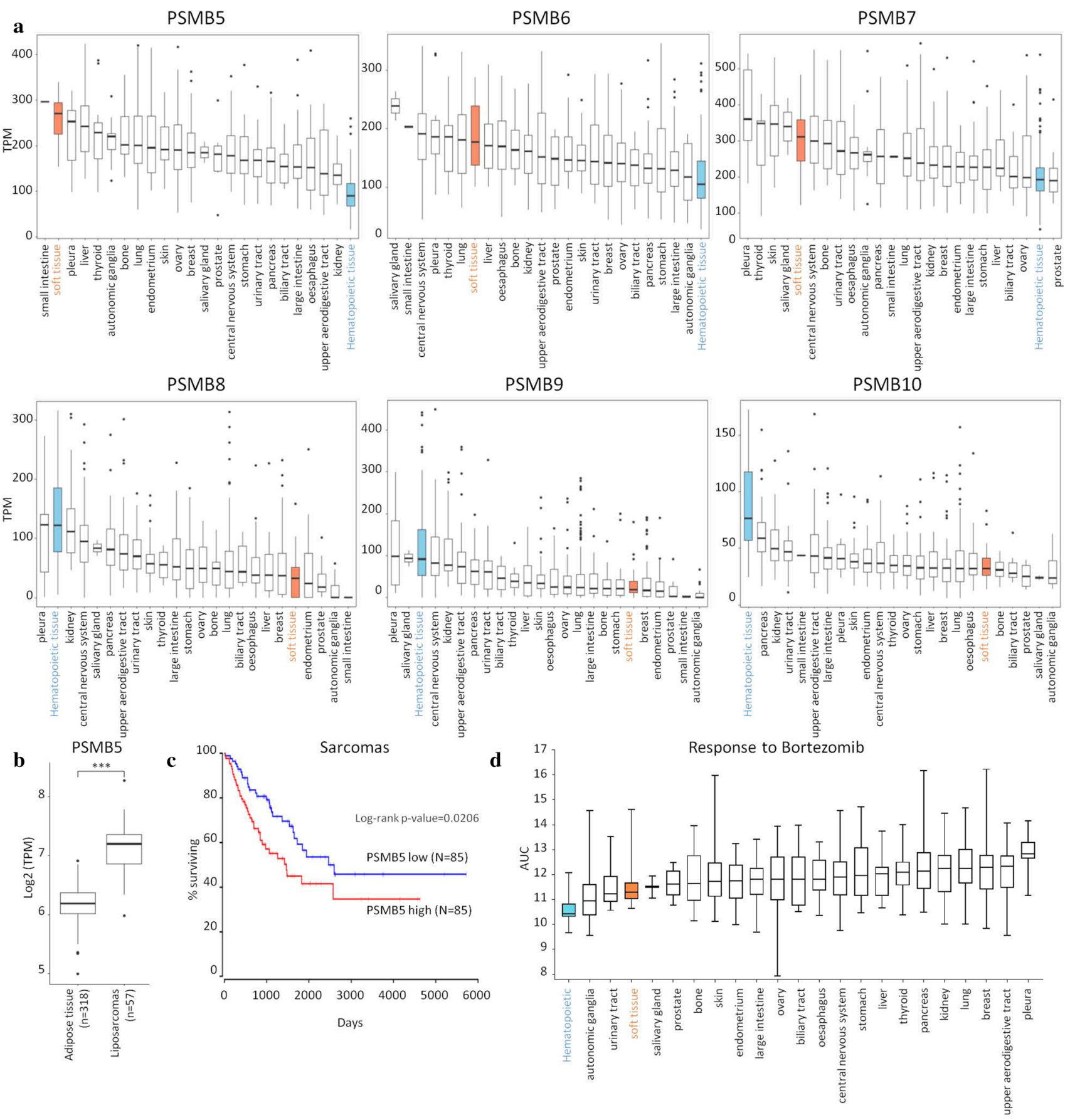

Fig. 1 PSMB5 is over-expressed in soft tissue sarcomas and is associated with a poor clinical outcome. a Expression of constitutive proteasome subunits (PSMB5, PSMB6, PSMB7) and immunoproteasome subunits (PSMB8, PSMB9, PSMB10) in cell lines encompassing different cancer types. TPM (Transcripts PerKilobase Million) values are plotted with a cut-off of 0.99 percentile. b PSMB5 expression in liposarcoma patient samples (TCGA) and normal adipose tissue samples (GTex). N represents the number of samples. Statistical signifi-

cance was tested using the Wilcoxon rank-sum test. c Kaplan-Meier plot showing survival correlation with PSMB5 expression in sarcomas. Values are available in TCGA and were analysed using Oncolnc portal (http://www.oncolnc.org/) [48]. Lower and upper (33:33) percentiles of patients were compared ( $N=85$ for each group). d Profiling of response to bortezomib across cell lines belonging to different cancer types. AUC values are downloaded from CTRP (Cancer Therapeutic Response Portal). A lower AUC indicates higher sensitivity 

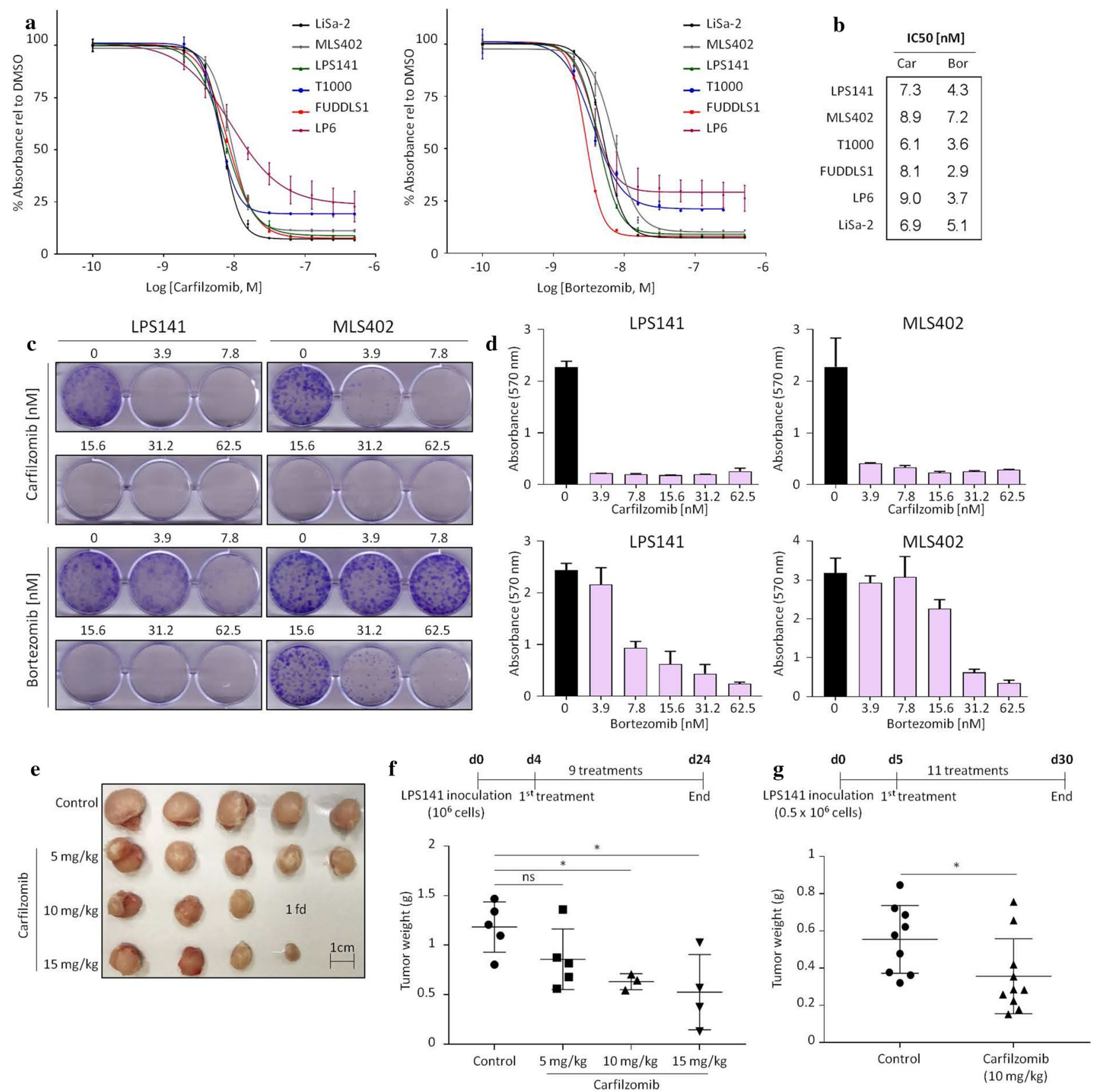

Fig. 2 Carfilzomib reduces the viability of liposarcoma cell lines in vitro and in vivo. a Dose-response curves of LPS cell lines treated with carfilzomib or bortezomib. Values represent mean $\pm \mathrm{SD}$ of at least two experiments performed in triplicate. b IC50 values from the experiment shown in a using GraphPad Prism 7 software. c Representative clonogenic assay of LPS cells in the presence of proteasome inhibitors. d Absorbance quantification of the clonogenic assays shown in c. Values are mean $\pm \mathrm{SD}$ of duplicate. e Tumors excised from mice treated with either vehicle control or carfilzomib. $(\mathrm{fd}=$ found dead during the experiment). f Experimental design and weight of tumors from the experiment shown in e (ns=not significant, $* p<0.05$, as determined by two-tailed Mann-Whitney test). $\mathbf{g}$ Experimental design and weight of tumors from mice treated with vehicle control or carfilzomib $(* p<0.05$, as determined by two-tailed Mann-Whitney test) 

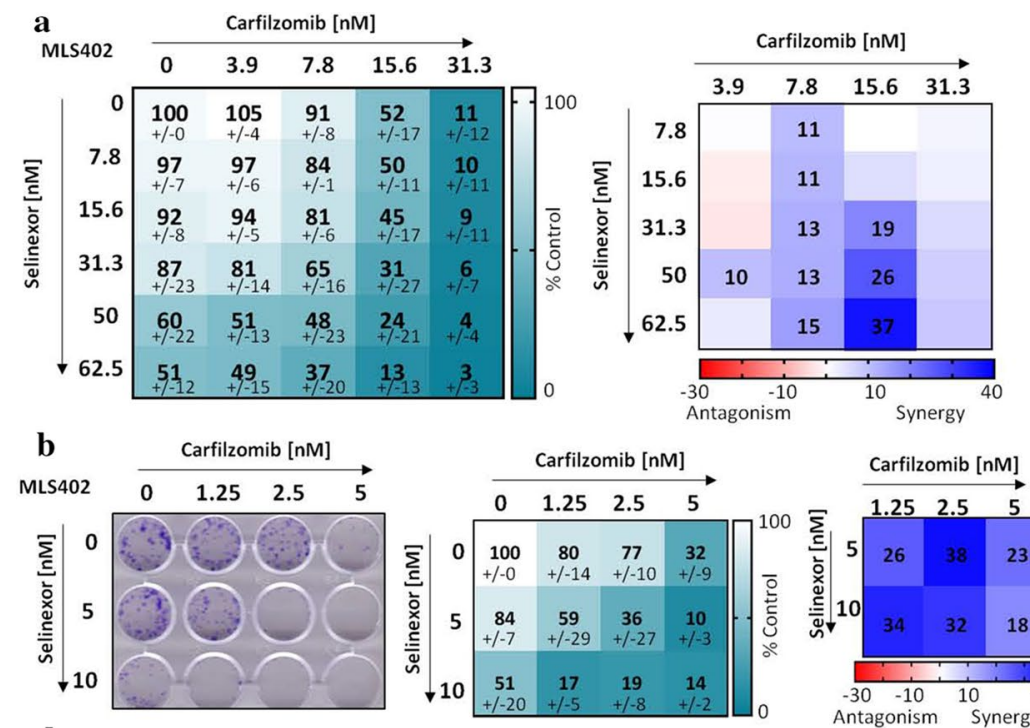

d

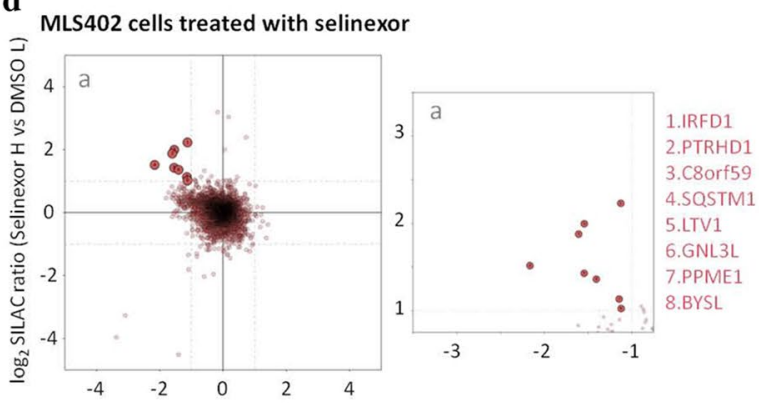

$\log _{2}$ SILAC ratio (Selinexor L vs DMSO H)
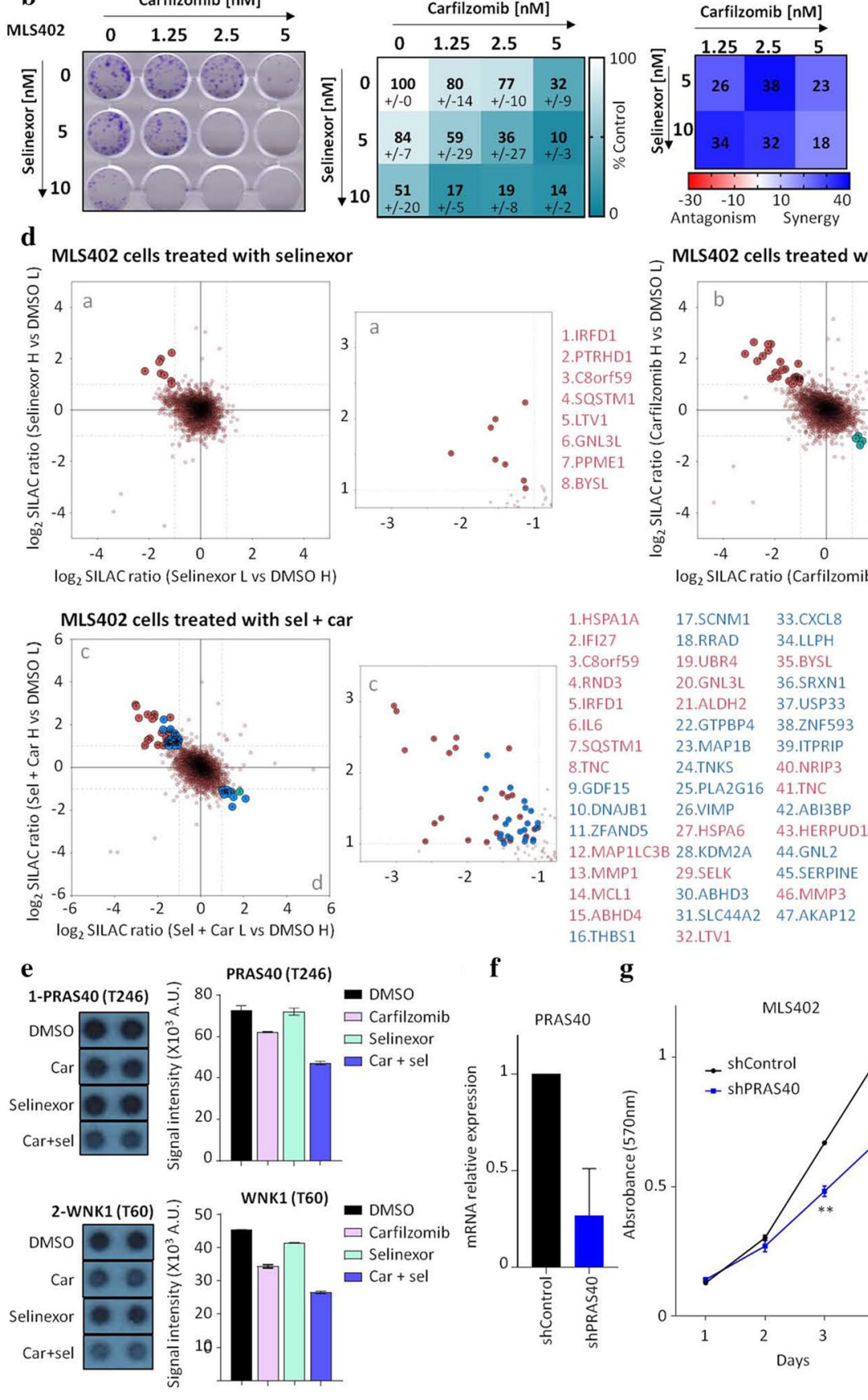

f $\quad$ g
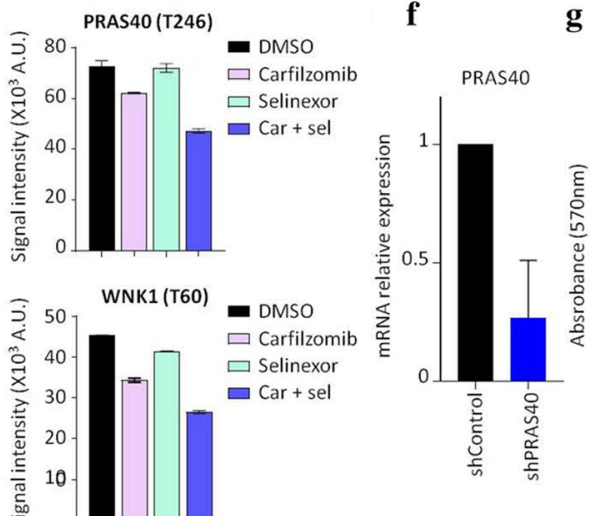

c

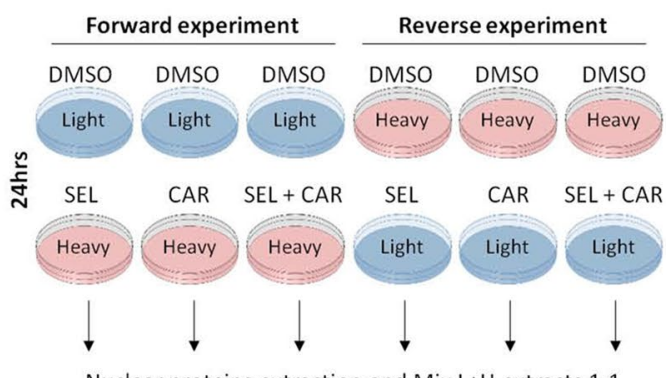

Nuclear proteins extraction and Mix L+H extracts $1: 1$<smiles>[C+]1=CC=CC1</smiles>

SDS-PAGE and in gel digestion

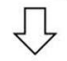

LC-MS/MS analysis

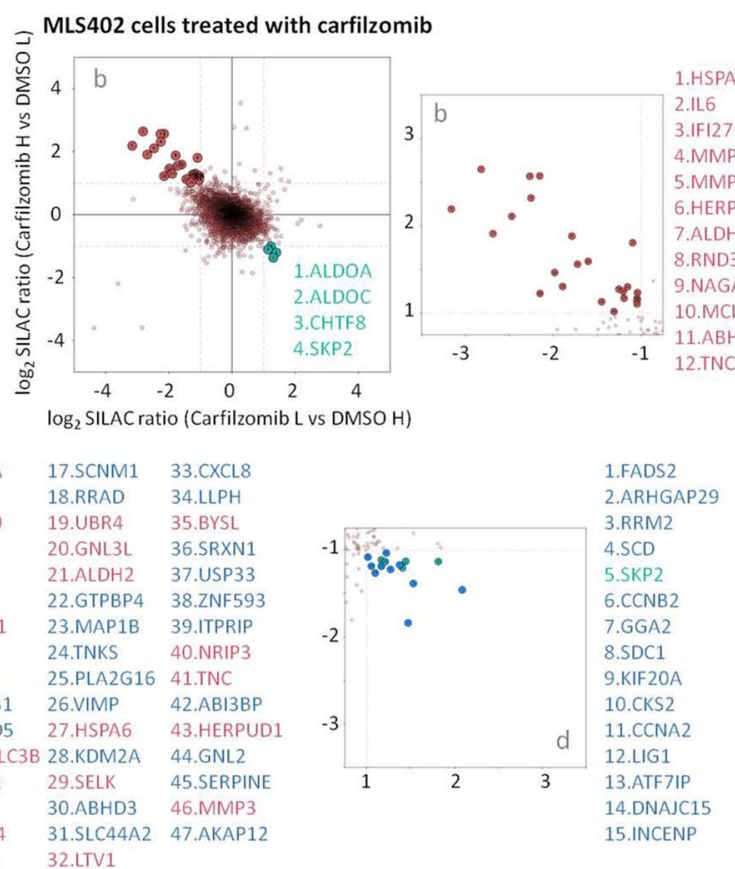

h $\mathbf{i}$

g h

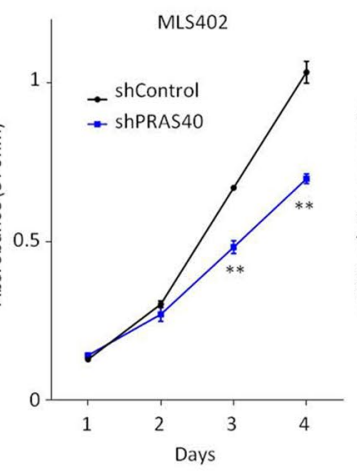

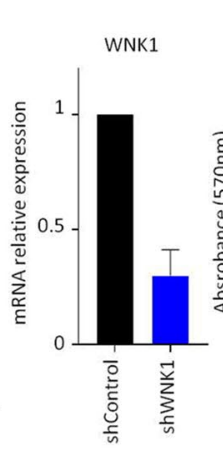

i

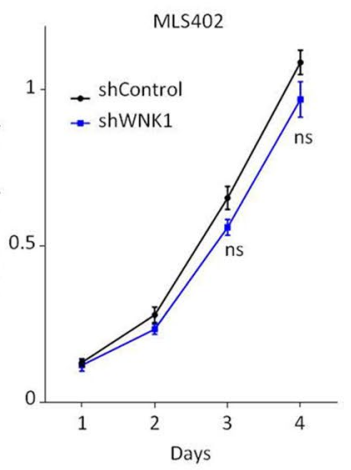


४Fig. 3 Selinexor potentiates effects of carfilzomib in LPS. a Viability assays of MLS402 cells treated with either carfilzomib, selinexor or combinations of both $(n=2$ experiments performed in duplicate, values indicate mean $\pm \mathrm{SD}$ ). Right panels: heatmaps of HSA (ighest $\underline{\text { Single }}$ Agent) synergy and antagonism scores generated using Combenefit Software [49]. A score $<-10$ shows antagonism, a score between -10 and 10 shows the additive effect and a score $>10$ depicts synergy between the drugs. Only scores $\geq 10$ are depicted. b Representative Colony formation assay of MLS402 cells treated with combinations of carfilzomib and selinexor. Middle panel represents relative absorbance values \pm SD. Right panel depicts the HSA scores. c Schematic of SILAC labeling of LPS cells in either 'heavy' or 'light' medium before drug treatment for $24 \mathrm{~h}$, and subsequent nuclear proteins extraction and processing for LC-MS/MS analysis. d Two-dimensional SILAC ratio plots showing quantified proteins by mass spectrometry analysis in MLS402 cells treated with either selinexor $(60 \mathrm{nM})$, carfilzomib $(15 \mathrm{nM})$ or their combination. Proteins in the top left quadrant of each plot are accumulated after drug treatment $(\log 2$ fold change $>1)$, while those on the bottom right are depleted $(\log 2$ fold change $<-1)$. Smaller panels are enlarged view of the annotated quadrants (a-d). Accumulated (in red) or depleted (in green) proteins are annotated. Proteins in blue are those differentially expressed only in the drug combination treatment. e Quantification of signal intensities of two phosphorylated kinases (PRAS40 and WNK1) from phospho-kinase arrays of MLS402 treated with either DMSO, carfilzomib (15 nM), selinexor $(60 \mathrm{nM})$ or a combination of both. Left panels are a magnification of highlighted spots in (Supplementary Figure S2C). Right panels show the mean \pm SD of signal intensities calculated using Image Studio Lite software. f, h qRT-PCR analysis of relative expression of PRAS40 or WNK1 transcripts in MLS402 cells transduced with either shControl or shPRAS40 (f) or shWNK1 (h). Values represent mean \pm SEM of three experiments. $g$, i Growth curves of MLS402 shControl and shPRAS40 or shWNK1 cells. Values represent mean $\pm \mathrm{SEM}$ of at least two experiments performed in triplicate. (ns $=$ not significant, ${ }^{*} p<0.01$, as determined by two-tailed Mann-Whitney test)

more than 6900 proteins were identified and an approximate average of 5700 proteins were quantified with H/L SILAC ratios (Supplementary Table 1). Eight proteins accumulated in cells treated with selinexor alone ( $\log 2$ (fold change) $>1$ ), among which SQSTM1 (a modulator of autophagy of ubiquitinated protein aggregates), LTV1 (a ribosome biogenesis factor), GNL3L (required for ribosomal pre-rRNA processing), and BYSL (essential for the 18S rRNA processing and 40S subunit biogenesis) have been reported to be XPO1 targets [23, 24] (Fig. 3d). Carfilzomib treatment alone induced accumulation of 24 proteins, especially HSPA1A (a proteotoxic stress-induced protein), and depletion of four proteins (Fig. 3d). Differentially expressed proteins (DEPs) identified in drug combination and their corresponding $\mathrm{H} / \mathrm{L}$ ratios in single treatments are listed in Supplementary Table 1. Some of these DEPs were not measured in single treatments, while other proteins showed a similar expression change tendency in single treatments, and the differential expression became significant and met our threshold criteria only in drug combination (Supplementary Table 1). Interestingly, combining selinexor and carfilzomib resulted in accumulation of other novel proteins, including more proteins required for ribosome biogenesis (GNL2; required for nuclear export and maturation of pre-60S ribosomal subunits, and GTPBP4; potentially involved in the biogenesis of the pre-60S ribosomal subunits [25, 26]), and stress-induced proteins (DNAJB1). These results suggest that this drug combination potentiates each drug's effects, such as further disrupting ribosome biogenesis and further inducing stress response. Moreover, several proteins were depleted in the combinational treatment, among which FADS2 (Fatty Acid Desaturase 2) was the most depleted.

To identify additional mechanisms contributing to the anti-cancer synergistic effect of selinexor and carfilzomib, we assessed the impact of the drug combination on major signaling pathways. Phospho-kinase arrays of MLS402 cells were profiled after $24 \mathrm{~h}$ of treatment with either carfilzomib or selinexor alone, or in combination (Supplementary Figure S2c). Carfilzomib and selinexor alone did not induce significant effects on most kinases, while a combination of both drugs reduced the phosphorylation of two proteins: WNK1 and PRAS40 (Fig. 3e), without affecting the reference spots (Supplementary Figure S2d). WNK1 (WNK lysine deficient protein kinase 1) is a serine/threonine kinase regulating ion transport pathways [27], while PRAS40 (or AKT1S1, Proline-rich Akt1 substrate 1) contributes, among others, to PI3K/Akt and mTOR signaling [28]. Knock-down of PRAS40 (Fig. 3f, g), but not WNK1 (Fig. 3h, i), led to a decrease in MLS402 cell viability. These results highlight an additional mechanistic synergy between carfilzomib and selinexor, potentially leading to the combination's anti-proliferative effects.

\section{Proteomic profiles of proteasome inhibition-induced cellular changes in LPS}

To identify other combinational approaches, global protein expression changes induced by proteasome inhibitors were profiled by quantitative mass spectrometry. Cells cultured in Heavy (H) or Light (L) medium were treated for $24 \mathrm{~h}$ with carfilzomib (80 $\mathrm{nM})$ or bortezomib $(40 \mathrm{nM})$ and compared to DMSO-treated cells (Fig. 4a). Treating LPS cells with these inhibitors induced the accumulation of ubiquitinated proteins (Fig. 4b), demonstrating an efficient inhibition of the UPS. 


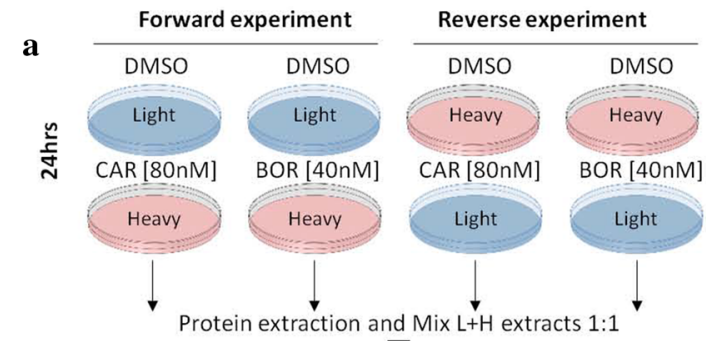

$\sqrt{5}$

SDS-PAGE and in gel digestion<smiles>C1CC2CCC2C1</smiles>

LC-MS/MS analysis

c Forward Reverse LPS141 MLS402 LPS141 MLS402 応
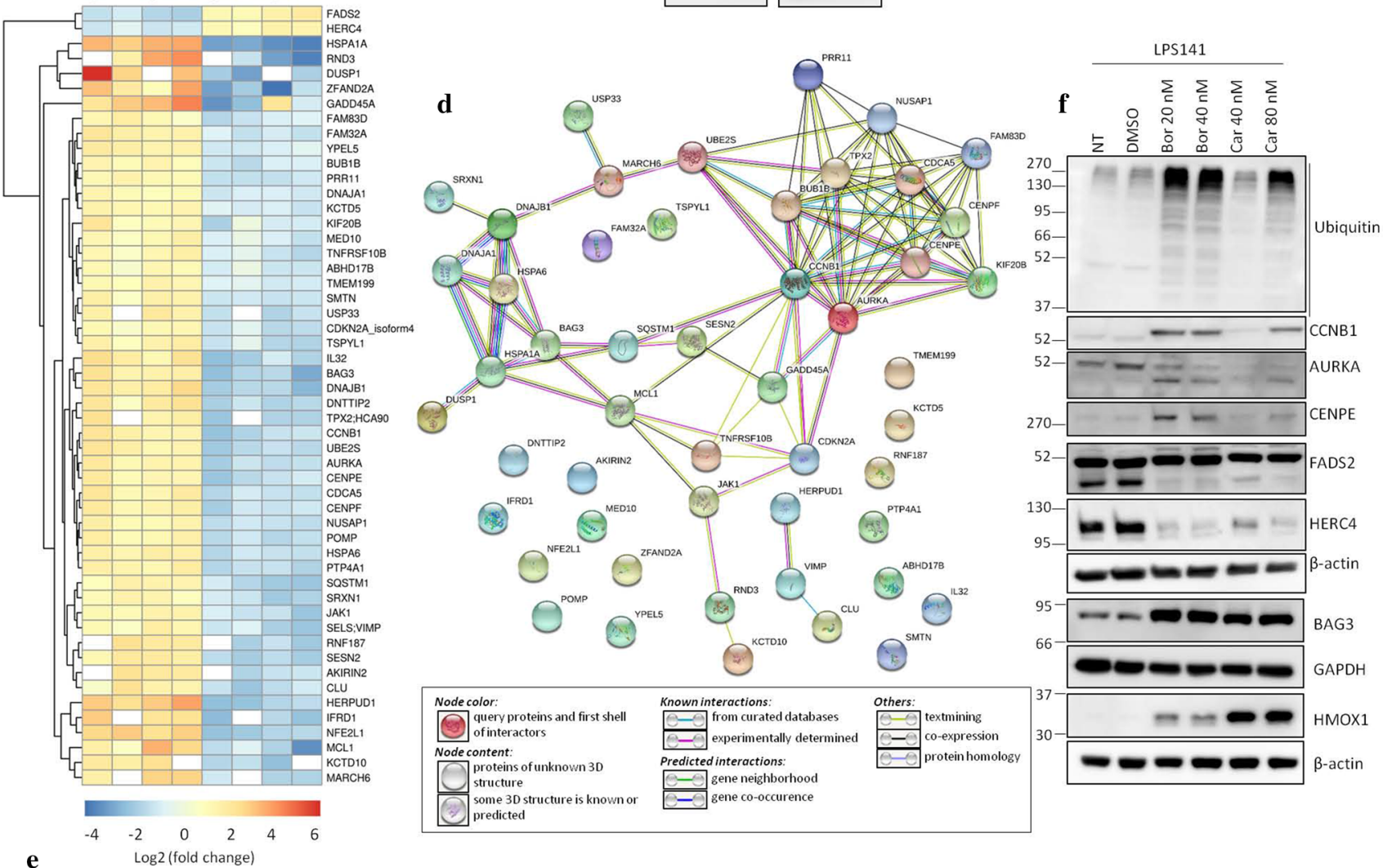

\begin{tabular}{llcc}
\hline \multicolumn{4}{c}{ Biological process $(\mathrm{GO})$} \\
\hline GO-term ID & Term description & Count in gene set & \\
\hline GO:000708se discovery rate & regulation of mitotic nuclear division & 10 of 160 & $2.45 \mathrm{E}-08$ \\
GO:0030163 protein catabolic process & 15 of 615 & $2.45 \mathrm{E}-08$ \\
GO:0022402 & cell cycle process & 16 of 890 & $1.86 \mathrm{E}-07$ \\
GO:0033554 cellular response to stress & 20 of 1553 & $1.86 \mathrm{E}-07$ \\
GO:0007049 cell cycle & 18 of 1263 & $2.95 \mathrm{E}-07$ \\
\hline
\end{tabular}

Fig. 4 SILAC-based quantitative mass spectrometry analyses of LPS cells treated with proteasome inhibitors. a Schematic of SILAC labeling of LPS cells in either 'heavy' or 'light' medium before drug treatment for $24 \mathrm{~h}$, and subsequent protein extraction for LC-MS/MS analysis. b Western blots showing accumulation of ubiquitinated proteins in LPS141 extracts used in proteomic analyses. $\beta$-actin serves as a loading control. c Heatmap of $\log 2$ fold changes $(\log 2 \mathrm{fc})$ of proteins differentially expressed in LPS141 or MLS402 cells treated with either carfilzomib (car) or bortezomib (bor). The 'forward' col-

\begin{tabular}{llcc}
\hline \multicolumn{4}{c}{ KEGG pathways } \\
\hline Pathway & Term description & Count in gene set & False discovery rate \\
\hline hsa04141 & Protein processing in endoplasmic reticulum & 7 of 161 & $1.46 E-05$ \\
hsa04115 & p53 signaling pathway & 5 of 68 & $3.87 \mathrm{E}-05$ \\
hsa05164 Influenza A & 5 of 168 & 0.0017 \\
hsa04110 Cell cycle & 4 of 123 & 0.0051 \\
hsa05162 & Measles & 4 of 123 & 0.0055 \\
\hline
\end{tabular}

umns represent the $\log 2 \mathrm{fc}$ when comparing car- or bor-treated cells grown in 'heavy' medium vs. DMSO-treated cells grown in 'light' medium. The 'reverse' columns represent the $\log 2 \mathrm{fc}$ when switching the SILAC labels for DMSO-treated cells vs. car- or bor-treated cells. d STRING analysis revealing nodes among the common up-regulated proteins following proteasome inhibition. e Biological processes and KEGG pathways enriched among the up-regulated proteins in $\mathbf{d}$. $\mathbf{f}$ Western blots validating a subset of targets identified in $\mathbf{c} . \beta$-actin and GAPDH serve as a loading control 
LC-MS/MS proteome analysis identified approximately 7000 proteins and about 5000 proteins were quantified with $\mathrm{H} / \mathrm{L}$ SILAC ratios in both forward and reverse experiments for each condition (Supplementary Table 2). Fifty proteins accumulated ( $\log 2$ (fold change) $>1$ ) in both cell lines in at least six out of eight conditions after proteasome inhibition, while only two proteins, FADS2 and HERC4, were commonly down-regulated ( $\log 2$ (fold change) $<-1)$ (Fig. 4c; Supplementary Figure S3).

A STRING ( Search Tool for the Retrieval of Interacting Genes/Proteins) analysis (https://string-db.org) of the up-regulated proteins showed an enrichment of two protein groups; one regulating mitotic nuclear division and cell cycle process (e.g. CENPE, AURKA, TPX2, CCNB1) and another implicated in the cellular response to stress (e.g. BAG3, HSPA6, HSPA1A) (Fig. 4d, e). Either accumulation or reduction of some of the identified proteins were further validated by Western blot (Fig. 4f).

\section{Additive anti-cancer effect of carfilzomib and HSF1 inhibition}

To assess whether changes in protein levels result from transcriptional regulation, mRNA levels of some targets were measured. mRNA expression changes did not always correspond to protein level changes, and even showed an opposite effect in some cases (Supplementary Figure S4a). In agreement with protein quantifications, an induction of mRNAs of cellular stress response genes, such as HSPA6, HMOX1, BAG3, and IRFD1, was observed (Supplementary Figure S4B). Transcription of these genes can be induced by the stress-activated transcription factor HSF1 (Heat Shock Factor protein 1) [29, 30].

We tested whether a chemical inhibitor of HSF1 (KRIBB11) can further sensitize LPS cells to carfilzomib. In both viability (Supplementary Figures S4c-d) and clonogenic assays (Supplementary Figures S4e, f), combining KRIBB 11 and carfilzomib showed a mild synergy at some concentrations, while most of the combinations showed only additive effects.

\section{Carfilzomib and FADS2 inhibitor synergistically reduce $L P S$ viability}

Two proteins were down-regulated after proteasome inhibition: FADS2 (Fatty Acid Desaturase 2) and HERC4 (probable E3 ubiquitin-protein ligase HERC4) (Fig. 4c-f). Given their consistent down-regulation, and the fact that FADS2 was found down-regulated after combinational treatment of selinexor and carfilzomib (Fig. 3d), we tested whether FADS2 and HERC4 play a role in carfilzomib's anti-cancer effects. Due to the absence of HERC4 inhibitors, we downregulated HERC4 using siRNAs or CRISPR-Cas9 strategy and found that knocking-down HERC4 did not affect the survival of LPS cells nor their response to carfilzomib (data not shown).

FADS2 is a key enzyme implicated in the biosynthesis of polyunsaturated fatty acids [31]. FADS2 mRNA transcripts were down-regulated upon proteasome inhibition (Fig. 5a, b). To assess whether FADS2 down-regulation is detrimental for LPS cells, LPS cells were treated with a chemical inhibitor of FADS2 (SC26196) [32]. SC26196 reduced the viability of LPS cells and showed synergy when combined with carfilzomib in viability (Fig. 5c, d) and clonogenic assays (Fig. 5e, f). These observations demonstrate that FADS2 inhibition in LPS cells could enhance carfilzomib's anticancer potency.

\section{Drug library screen identifies novel carfilzomib-based drug combinations for LPS}

Since no FADS2 inhibitor is clinically approved to date, we searched for FDA (Food and Drug $\underline{\text { Administration)- }}$ approved drugs that could potentiate carfilzomib's efficiency. Viability of LPS141 cells was assessed in the presence of 317 anti-cancer compounds, combined or not with carfilzomib (7.5 or $15 \mathrm{nM}$ ) (Fig. 6a). In this screen, carfilzomib at $7.5 \mathrm{nM}$ alone did not show an effect while at $15 \mathrm{nM}$ reduced viability by around $20 \%$ (Fig. 6b). Compared to DMSOtreated plates, drugs that induced either $>20 \%$ or $>40 \%$ of decreased viability in the carfilzomib $[7.5 \mathrm{nM}]$ or $[15 \mathrm{nM}]-$ treated plates, respectively, were identified (Fig. 6c; Supplementary Figure S5a). Thirty-seven drugs, of which seven are HDAC inhibitors, showed potential synergy with carfilzomib (Supplementary Figure S5a). Six drugs (cyclosporin A, medroxyprogesterone acetate, abexinostat, aprepitant, GSK1904529A and pracinostat) were identified in both screens. Synergies between carfilzomib and either abexinostat or pracinostat (two HDAC inhibitors) were subsequently validated (Fig. 6d, Supplementary Figure S5b). Likewise, the synergy between carfilzomib and cyclosporin A was confirmed (Fig. 6e). In vivo, cyclosporin A (at $10 \mathrm{mg} /$ $\mathrm{kg}$ ) significantly reduced tumor burden when combined with carfilzomib, but not when administered alone (Fig. 6f). This combination did not affect the mice body weight (Supplementary Figure S5c), showing that combining carfilzomib 

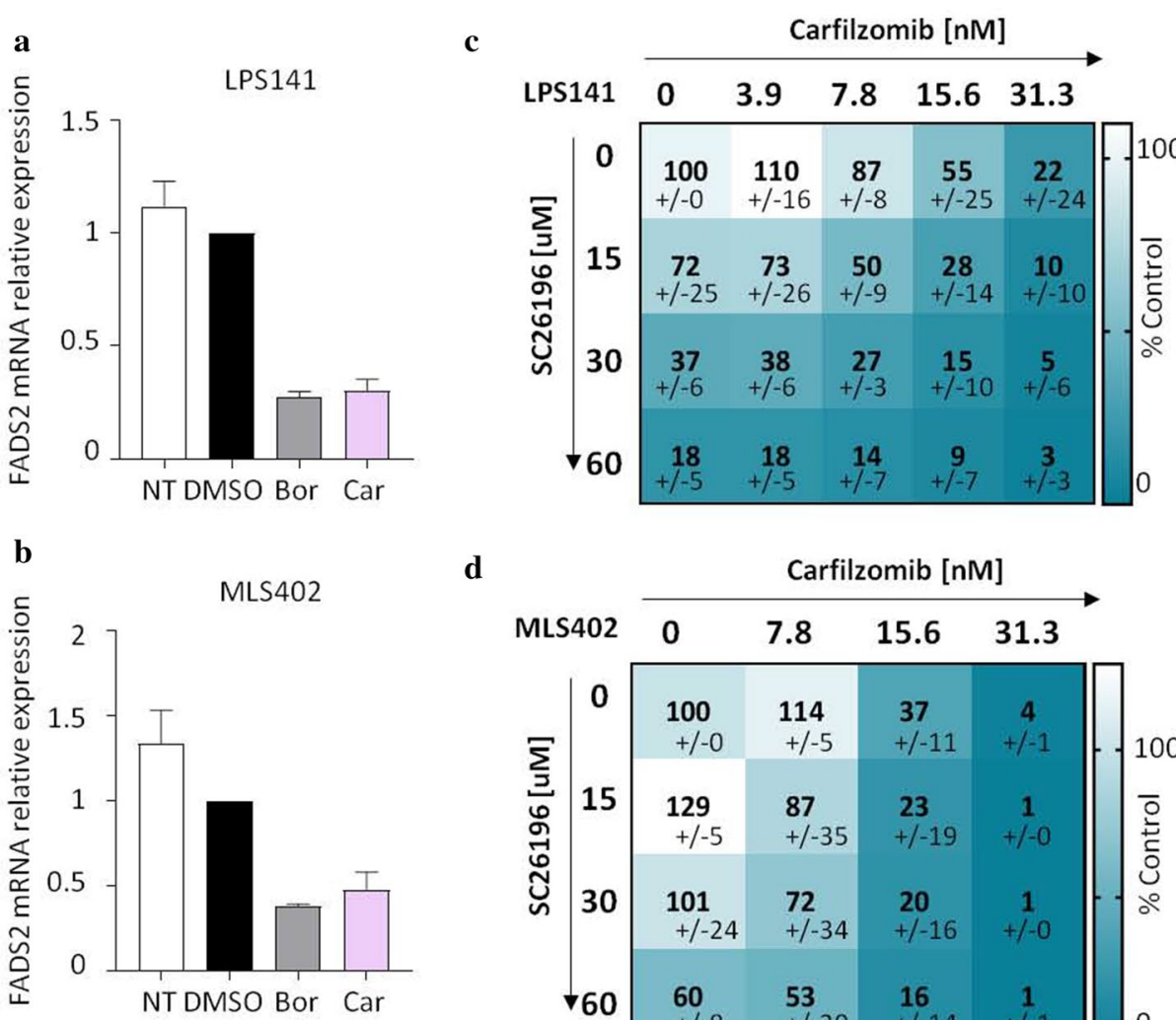

d

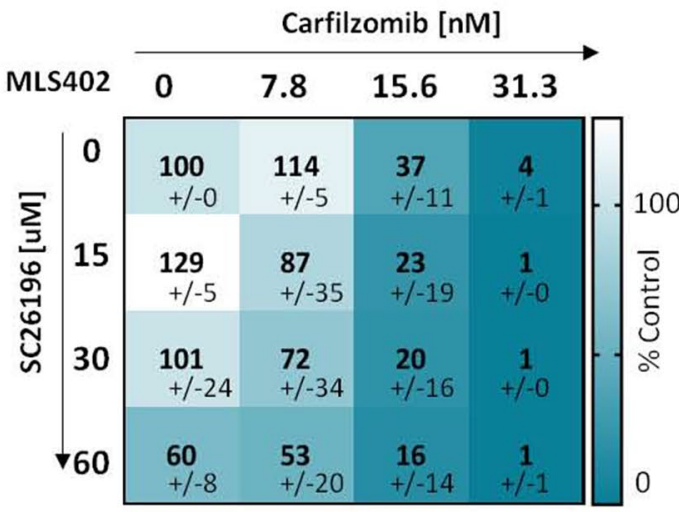

Carfilzomib [nM]

$3.9 \quad 7.8 \quad 15.631 .3$

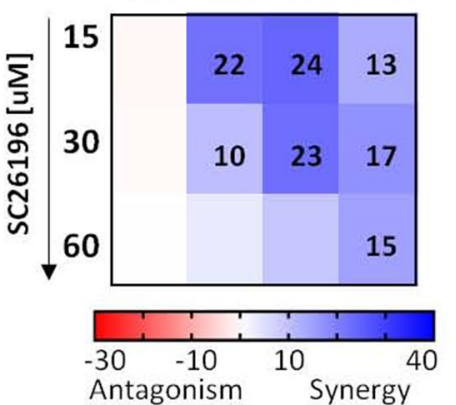

Carfilzomib [nM]

$\begin{array}{lll}7.8 & 15.6 & 31.3\end{array}$

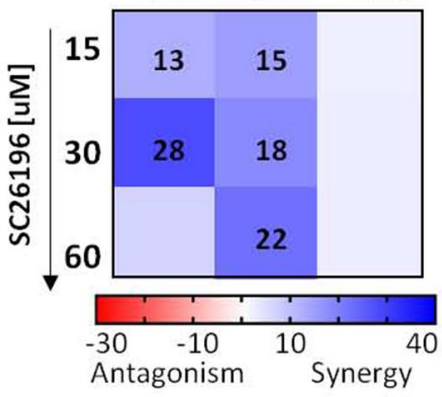

e
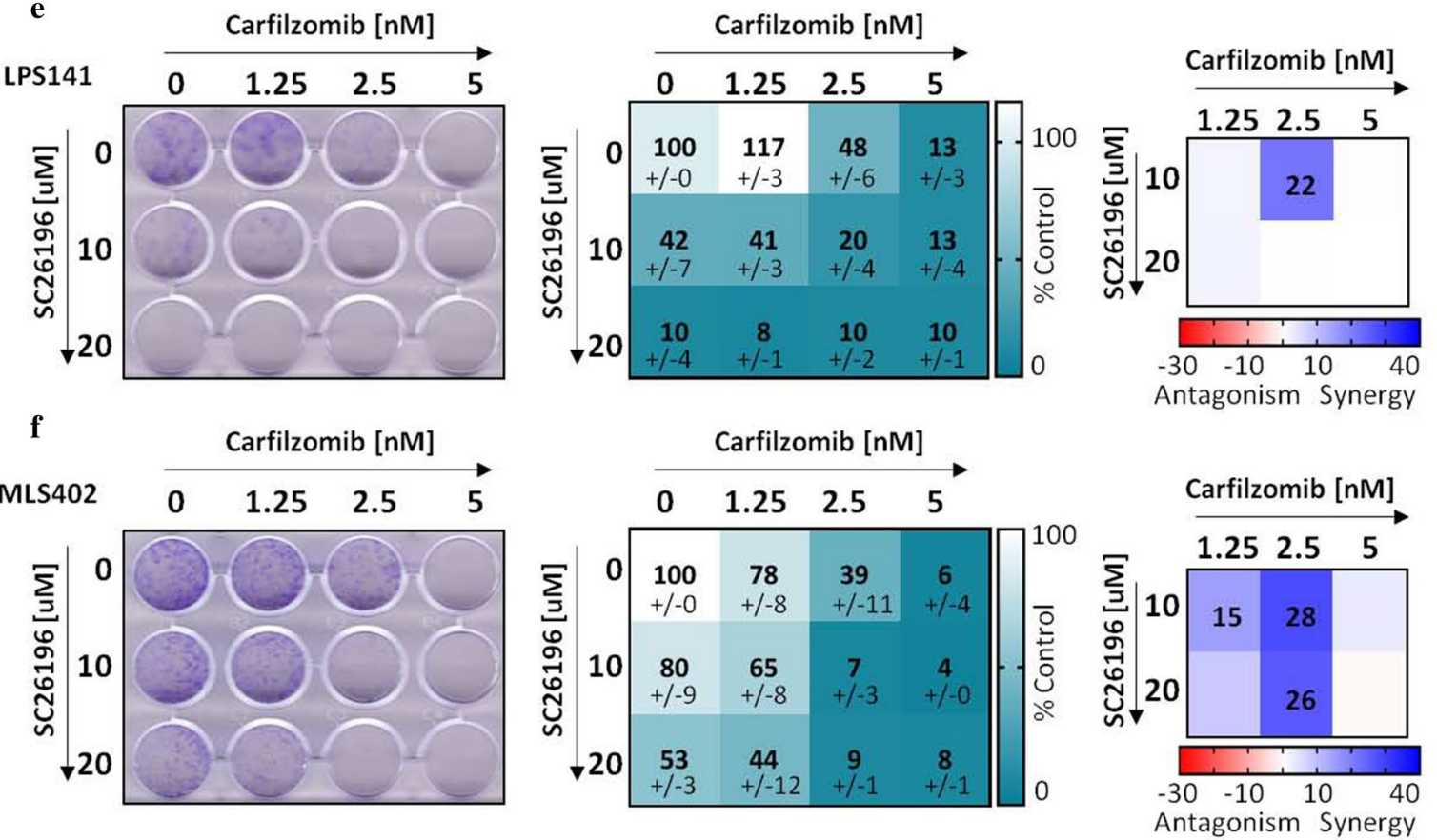

Fig. 5 Carfilzomib and FADS2 inhibitor can synergistically reduce LPS viability. a, b qRT-PCR showing mRNA relative expression of FADS2 in LPS141 (a) or MLS402 (b) cells non-treated (NT), treated with either DMSO, bortezomib $(40 \mathrm{nM})$ or carfilzomib $(80 \mathrm{nM})$ for $24 \mathrm{~h}$. Values represent mean \pm SEM of at least two experiments. c, d Left panels: heatmaps depict viability in either LPS141 (c) or MLS402 (d) cell lines after treatment with either SC26196 (FADS2 inhibitor) or carfilzomib or combinations of both. Values represent mean \pm SD of percentage of absorbance relative to DMSO of at least two experiments performed in duplicate. Right panel is a heatmap of the HSA scores. e, $\mathbf{f}$ Representative clonogenic assays after treatment of LPS141 (e) and MLS402 (f) cell lines with combinations of carfilzomib and SC26196. Left panels are representative images of the assays. Middle panels represent relative absorbance values of each condition. Values are mean \pm SD. Right panels depict the HSA synergistic scores $(>10)$ 
and cyclosporin A represents a safe and efficacious potential strategy for LPS treatment.

\section{Discussion}

Although proteasome inhibition (PI) has become a cornerstone in the clinical management of MM, proteasome inhibitors have been disappointing in solid cancers. Here, we show that carfilzomib is potent against liposarcomas, alone or in combinational treatment.

Selinexor, a nuclear transport inhibitor recently approved by the US FDA for MM [33], has shown anti-cancer activity in patients with dedifferentiated LPS in a phase IB clinical study [34]. A recent study showed that selinexor potentiates carfilzomib's effects in sarcomas [12]. The authors proposed that this is due to NFkB inhibition, an observation reported in other cellular models $[19,21]$. XPO1 is responsible for nuclear export of various proteins, including newly assembled $40 \mathrm{~S}$ and $60 \mathrm{~S}$ ribosomal subunits $[35,36]$. In agreement with that, our nuclear proteome profiling indicated that combining selinexor and carfilzomib interferes with ribosome biogenesis networks. It was recently reported that selinexor synergizes with $\mathrm{Bcl}-\mathrm{xL}$ inhibitors to induce apoptosis in cancer cells, by impeding rRNA processing and reducing levels of mature rRNAs, necessary for protein translation [37]. A similar concerted action of selinexor and carfilzomib on protein synthesis may be one of the causes leading to reduced LPS cell viability. Additionally, we identified another probable mode of action of this combination: inhibition of PRAS40, a pro-survival protein.

Various events have been previously described as contributors to PI-induced cell death, including induction of endoplasmic reticulum (ER)-stress, induction of apoptosis and/ or inhibition of NFkB pathway [38]. We comprehensively delineated protein expression changes induced by PI in LPS cells, identified a recurrent down-regulation of FADS2 following PI, and demonstrated synergy between carfilzomib and an inhibitor of FADS2. FADS2 is a key enzyme of lipid metabolism and fatty acid biogenesis. These pathways are crucial to lipogenic malignancies [39] and were proposed as therapeutic targets in LPS [40]. Given the pro-tumoral roles of perturbed lipid metabolism in cancers [41], a dual inhibition of the proteasome and FADS2 could enhance the potency of proteasome inhibitors in solid cancers. In support of this, pharmacological inhibition of another key enzyme in the fatty acid synthesis pathway, FASN (Fatty Acid Synthase), enhanced the effects of bortezomib in prostate cancer cells [42].
Finally, through drug library screening, we identified more drugs synergizing with carfilzomib, such as cyclosporin A and HDAC inhibitors. Synergy between HDAC inhibitors and proteasome inhibitors has been documented in various types of cancers [43, 44]. Cyclosporin $\mathrm{A}$ is an immunosuppressive agent used to prevent organ rejection after transplantation as well as to treat several inflammatory disorders [45]. Clinical doses of cyclosporin A depend on its application. It can be given up to $20 \mathrm{mg} / \mathrm{kg}$ per day after organ transplantation; while in other diseases, it is used at lower doses [45]. Studies have investigated the use of low doses of cyclosporin A as anti-cancer therapy, mostly in combination with other drugs, and suggested that cyclosporin A may be valuable in cancer treatment [45-47]. The mechanisms underlying these effects are, however, unclear. We here showed that cyclosporin A potentiated carfilzomib's capacity to reduce tumor burden. A further optimization of the use of lower doses of cyclosporin A and a deeper understanding of the mode of actions of this combination would be worthwhile, given that cyclosporin A could represent an affordable anti-cancer drug.

Overall, we propose that carfilzomib could be repurposed to treat liposarcoma patients. We show that it can be used in the broad range of LPS subtypes, as a single agent, or in combination with other preclinical, clinical or FDAapproved drugs.

Authors' contributions MJ and HPK conceived the study and wrote the manuscript. MJ and AP performed experiments and analysed data. PD performed bioinformatics analysis. EP and WLT performed the drug library screen. VMu and DKap performed mass spectrometry analysis. VMa, DKan, YYJ, and YL contributed with reagents and discussions. All authors reviewed the final version of the paper. HPK supervised the study.

Funding This work is funded by the Singapore Ministry of Health's National Medical Research Council (NMRC) under its Singapore Translational Research (STaR) Investigator Award to H. Phillip Koeffler (NMRC/STaR/0021/2014); Singapore Ministry of Education Academic Research Fund Tier 2 (MOE2013-T2-2-150); the NMRC Centre Grant Programme awarded to National University Cancer Institute of Singapore (NMRC/CG/012/2013 and CGAug16M005); and the National Research Foundation Singapore and the Singapore Ministry of Education under its Research Centres of Excellence initiatives. This study was also supported by the National Institute of Health (NIH) R01 CA200992-04 grant to H. Phillip Koeffler, the Wendy Walk Foundation, and Karyopharm Therapeutics. We also thank Aaron Eschman and the Melmed family for their support. MJ is a recipient of an NTU presidential postdoctoral fellowship.

Availability of data and materials The mass spectrometry proteomics data have been deposited to the ProteomeXchange Consortium 

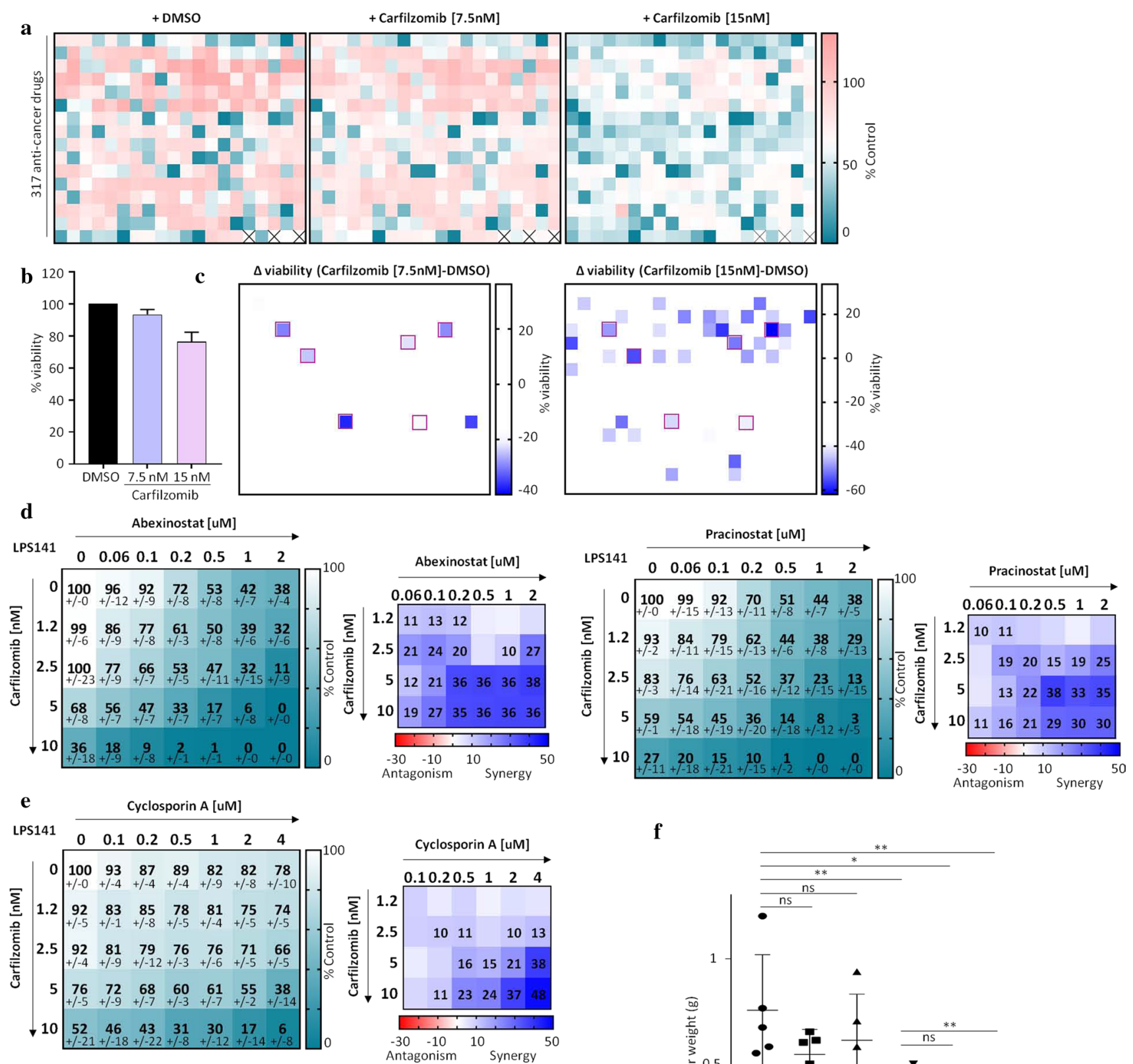

\section{f}

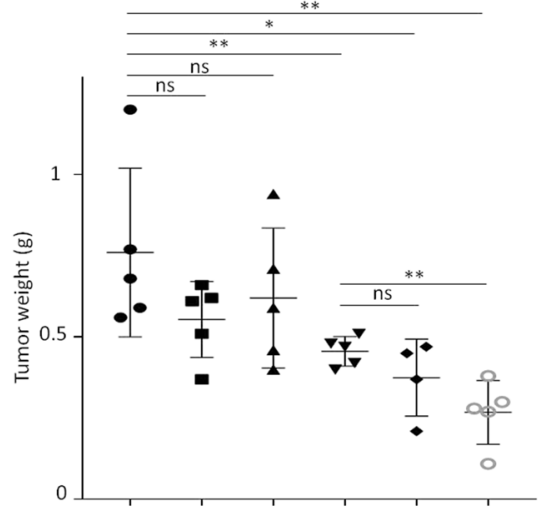

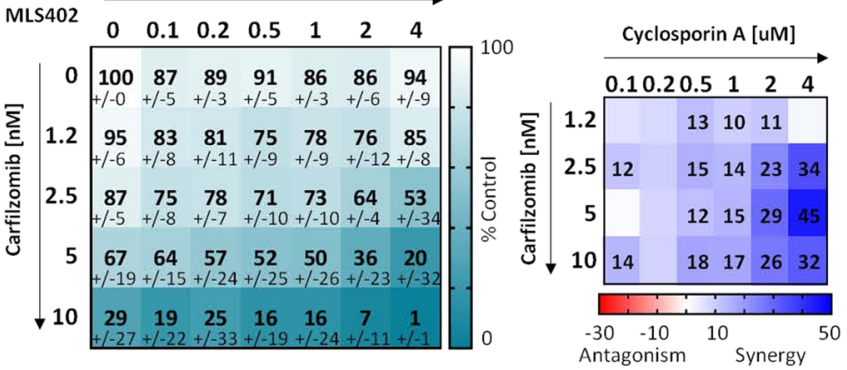

Vehicle 1

Cyclosporin A (3 mg/kg)

Cyclosporin A (10 mg $/ \mathrm{kg})$

Carfilzomib (10 mg/kg) 
४Fig. 6 Drug library screen identifies novel carfilzomib-based drug combinations for LPS. a Drug library screening of LPS141 cells. Each heatmap represents viability as a percentage relative to control cells, assessed by Cell-titer Glo. Values represent the average of at least two replicates of plates treated in addition with either DMSO, carfilzomib $(7.5 \mathrm{nM})$ or carfilzomib $(15 \mathrm{nM})$. b Percentage of the viability of LPS141 cells treated with either $7.5 \mathrm{nM}$ or $15 \mathrm{nM}$ of carfilzomib alone in (6a). c Differential values of viability between carfilzomib (7.5 or $15 \mathrm{nM})$ and DMSO-treated cells. Wells highlighted with shades of blue represent a difference of at least either $20 \%$ (left panel) or $40 \%$ (right panel) of viability. Wells with red borders are drugs identified in both screens. d, e Viability assays of cells treated with combinations of carfilzomib and either abexinostat or pracinostat (d) or cyclosporin A (e) $(n=2$ experiments performed in duplicate; values are mean $\pm \mathrm{SD}$ ). Right panels are heatmaps of the HSA scores. f Weight of tumors from mice treated with either vehicle controls, 3 or $10 \mathrm{mg} / \mathrm{kg}$ of cyclosporin A, $10 \mathrm{mg} / \mathrm{kg}$ of carfilzomib or combinations of both. $\left({ }^{*} p<0.05,{ }^{*} p<0.01\right.$, ns $=$ not significant, as determined by two-tailed Mann-Whitney test)

via the PRIDE repository with the dataset identifiers PXD021001 and PXD020906.

\section{Compliance with ethical standards}

Conflict of interest Yosef Landesman is an employee of Karyopharm Therapeutics. The other authors declare no conflict of interest.

Ethics approval All in vivo experiments were performed in compliance with ethical regulations of Institutional Animal Care and Use Committee (IACUC) of National University of Singapore.

Open Access This article is licensed under a Creative Commons Attribution 4.0 International License, which permits use, sharing, adaptation, distribution and reproduction in any medium or format, as long as you give appropriate credit to the original author(s) and the source, provide a link to the Creative Commons licence, and indicate if changes were made. The images or other third party material in this article are included in the article's Creative Commons licence, unless indicated otherwise in a credit line to the material. If material is not included in the article's Creative Commons licence and your intended use is not permitted by statutory regulation or exceeds the permitted use, you will need to obtain permission directly from the copyright holder. To view a copy of this licence, visit http://creativecommons.org/licenses/by/4.0/.

\section{References}

1. Hochstrasser M (1995) Ubiquitin, proteasomes, and the regulation of intracellular protein degradation. Curr Opin Cell Biol 7(2):215-223

2. Demo SD, Kirk CJ, Aujay MA, Buchholz TJ, Dajee M, Ho MN, Jiang J, Laidig GJ, Lewis ER, Parlati F, Shenk KD, Smyth MS, Sun CM, Vallone MK, Woo TM, Molineaux CJ, Bennett MK (2007) Antitumor activity of PR-171, a novel irreversible inhibitor of the proteasome. Cancer Res 67(13):6383-6391. https://doi. org/10.1158/0008-5472.can-06-4086

3. Cavaletti G, Jakubowiak AJ (2010) Peripheral neuropathy during bortezomib treatment of multiple myeloma: a review of recent studies. Leuk Lymphoma 51(7):1178-1187. https://doi. org/10.3109/10428194.2010.483303
4. Huber EM, Basler M, Schwab R, Heinemeyer W, Kirk CJ, Groettrup M, Groll M (2012) Immuno- and constitutive proteasome crystal structures reveal differences in substrate and inhibitor specificity. Cell 148(4):727-738. https://doi.org/10.1016/j. cell.2011.12.030

5. Cromm PM, Crews CM (2017) The proteasome in modern drug discovery: second life of a highly valuable drug target. ACS Cent Sci 3(8):830-838. https://doi.org/10.1021/acscentsci.7b00252

6. Kane RC, Bross PF, Farrell AT, Pazdur R (2003) Velcade: U.S. FDA approval for the treatment of multiple myeloma progressing on prior therapy. Oncologist 8(6):508-513

7. Vij R (2012) Carfilzomib in multiple myeloma. Clin Adv Hematol Oncol 10(9):591-593

8. Huang Z, Wu Y, Zhou X, Xu J, Zhu W, Shu Y, Liu P (2014) Efficacy of therapy with bortezomib in solid tumors: a review based on 32 clinical trials. Future Oncol 10(10):1795-1807. https://doi. org/10.2217/fon. 14.30

9. Ducimetiere F, Lurkin A, Ranchere-Vince D, Decouvelaere AV, Peoc'h M, Istier L, Chalabreysse P, Muller C, Alberti L, Bringuier PP, Scoazec JY, Schott AM, Bergeron C, Cellier D, Blay JY, RayCoquard I (2011) Incidence of sarcoma histotypes and molecular subtypes in a prospective epidemiological study with central pathology review and molecular testing. PLoS ONE 6(8):e20294. https://doi.org/10.1371/journal.pone.0020294

10. Dei Tos AP (2000) Liposarcoma: new entities and evolving concepts. Ann Diagn Pathol 4(4):252-266. https://doi.org/10.1053/ adpa.2000.8133

11. Steen S, Stephenson G (2008) Current treatment of soft tissue sarcoma. Proc (Bayl Univ Med Cent) 21(4):392-396

12. Nair JS, Musi E, Schwartz GK (2017) Selinexor (KPT-330) induces tumor suppression through nuclear sequestration of IkappaB and downregulation of surviving. Clin Cancer Res 23(15):4301-4311. https://doi.org/10.1158/1078-0432. ccr-16-2632

13. Ghandi M, Huang FW, Jane-Valbuena J, Kryukov GV, Lo CC, McDonald ER 3rd, Barretina J, Gelfand ET, Bielski CM, Li H, Hu K, Andreev-Drakhlin AY, Kim J, Hess JM, Haas BJ, Aguet F, Weir BA, Rothberg MV, Paolella BR, Lawrence MS, Akbani R, Lu Y, Tiv HL, Gokhale PC, de Weck A, Mansour AA, Oh C, Shih J, Hadi K, Rosen Y, Bistline J, Venkatesan K, Reddy A, Sonkin D, Liu M, Lehar J, Korn JM, Porter DA, Jones MD, Golji J, Caponigro G, Taylor JE, Dunning CM, Creech AL, Warren AC, McFarland JM, Zamanighomi M, Kauffmann A, Stransky N, Imielinski M, Maruvka YE, Cherniack AD, Tsherniak A, Vazquez F, Jaffe JD, Lane AA, Weinstock DM, Johannessen CM, Morrissey MP, Stegmeier F, Schlegel R, Hahn WC, Getz G, Mills GB, Boehm JS, Golub TR, Garraway LA, Sellers WR (2019) Next-generation characterization of the cancer cell line encyclopedia. Nature 569(7757):503-508. https://doi.org/10.1038/s41586-019-1186-3

14. Consortium GT (2013) The genotype-tissue expression (GTEx) project. Nat Genet 45(6):580-585. https://doi.org/10.1038/ ng. 2653

15. Cancer Genome Atlas Research, Weinstein JN, Collisson EA, Mills GB, Shaw KR, Ozenberger BA, Ellrott K, Shmulevich I, Sander C, Stuart JM (2013) The cancer genome atlas pan-cancer analysis project. Nat Genet 45(10):1113-1120. https://doi. org/10.1038/ng.2764

16. Vivian J, Rao AA, Nothaft FA, Ketchum C, Armstrong J, Novak A, Pfeil J, Narkizian J, Deran AD, Musselman-Brown A, Schmidt H, Amstutz P, Craft B, Goldman M, Rosenbloom K, Cline M, O'Connor B, Hanna M, Birger C, Kent WJ, Patterson DA, Joseph AD, Zhu J, Zaranek S, Getz G, Haussler D, Paten B (2017) Toil enables reproducible, open source, big biomedical data analyses. Nat Biotechnol 35(4):314-316. https://doi.org/10.1038/nbt.3772

17. Basu A, Bodycombe NE, Cheah JH, Price EV, Liu K, Schaefer GI, Ebright RY, Stewart ML, Ito D, Wang S, Bracha AL, Liefeld 
T, Wawer M, Gilbert JC, Wilson AJ, Stransky N, Kryukov GV, Dancik V, Barretina J, Garraway LA, Hon CS, Munoz B, Bittker JA, Stockwell BR, Khabele D, Stern AM, Clemons PA, Shamji AF, Schreiber SL (2013) An interactive resource to identify cancer genetic and lineage dependencies targeted by small molecules. Cell 154(5):1151-1161. https://doi.org/10.1016/j.cell.2013.08.003

18. Kanojia D, Garg M, Martinez J, Ta M, Luty SB, Doan NB, Said JW, Forscher C, Tyner JW, Koeffler HP (2017) Kinase profiling of liposarcomas using RNAi and drug screening assays identified druggable targets. J Hematol Oncol 10(1):173. https://doi. org/10.1186/s13045-017-0540-x

19. Kashyap T, Argueta C, Aboukameel A, Unger TJ, Klebanov B, Mohammad RM, Muqbil I, Azmi AS, Drolen C, Senapedis W, Lee M, Kauffman M, Shacham S, Landesman Y (2016) Selinexor, a Selective Inhibitor of Nuclear Export (SINE) compound, acts through NF-kappaB deactivation and combines with proteasome inhibitors to synergistically induce tumor cell death. Oncotarget 7(48):78883-78895. https://doi.org/10.18632/oncotarget.12428

20. Rosebeck S, Alonge MM, Kandarpa M, Mayampurath A, Volchenboum SL, Jasielec J, Dytfeld D, Maxwell SP, Kraftson SJ, McCauley D, Shacham S, Kauffman M, Jakubowiak AJ (2016) Synergistic myeloma cell death via novel intracellular activation of caspase-10-dependent apoptosis by carfilzomib and selinexor. Mol Cancer Ther 15(1):60-71. https://doi.org/10.1158/15357163.mct-15-0488

21. Turner JG, Kashyap T, Dawson JL, Gomez J, Bauer AA, Grant S, Dai Y, Shain KH, Meads M, Landesman Y, Sullivan DM (2016) XPO1 inhibitor combination therapy with bortezomib or carfilzomib induces nuclear localization of IkappaBalpha and overcomes acquired proteasome inhibitor resistance in human multiple myeloma. Oncotarget 7(48):78896-78909. https://doi. org/10.18632/oncotarget.12969

22. Garg M, Kanojia D, Mayakonda A, Said JW, Doan NB, Chien W, Ganesan TS, Chuang LS, Venkatachalam N, Baloglu E, Shacham S, Kauffman M, Koeffler HP (2017) Molecular mechanism and therapeutic implications of selinexor (KPT-330) in liposarcoma. Oncotarget 8(5):7521-7532. https://doi.org/10.18632 /oncotarget.13485

23. Thakar K, Karaca S, Port SA, Urlaub H, Kehlenbach RH (2013) Identification of CRM1-dependent nuclear export cargos using quantitative mass spectrometry. Mol Cell Proteomics 12(3):664-678. https://doi.org/10.1074/mcp.m112.024877

24. Conforti F, Zhang X, Rao G, De Pas T, Yonemori Y, Rodriguez JA, McCutcheon JN, Rahhal R, Alberobello AT, Wang Y, Zhang YW, Guha U, Giaccone G (2017) Therapeutic effects of XPO1 inhibition in thymic epithelial tumors. Cancer Res 77(20):5614 5627. https://doi.org/10.1158/0008-5472.can-17-1323

25. Wild T, Horvath P, Wyler E, Widmann B, Badertscher L, Zemp I, Kozak K, Csucs G, Lund E, Kutay U (2010) A protein inventory of human ribosome biogenesis reveals an essential function of exportin 5 in 60S subunit export. PLoS Biol 8(10):e1000522. https://doi.org/10.1371/journal.pbio.1000522

26. Wu S, Tutuncuoglu B, Yan K, Brown H, Zhang Y, Tan D, Gamalinda M, Yuan Y, Li Z, Jakovljevic J, Ma C, Lei J, Dong MQ, Woolford JL Jr, Gao N (2016) Diverse roles of assembly factors revealed by structures of late nuclear pre-60S ribosomes. Nature 534(7605):133-137. https://doi.org/10.1038/nature 17942

27. Rodan AR, Jenny A (2017) WNK kinases in development and disease. Curr Top Dev Biol 123:1-47. https://doi.org/10.1016/ bs.ctdb.2016.08.004

28. Lv D, Guo L, Zhang T, Huang L (2017) PRAS40 signaling in tumor. Oncotarget 8(40):69076-69085. https://doi.org/10.18632 /oncotarget.17299
29. Gomez-Pastor R, Burchfiel ET, Thiele DJ (2018) Regulation of heat shock transcription factors and their roles in physiology and disease. Nat Rev Mol Cell Biol 19(1):4-19. https://doi. org/10.1038/nrm.2017.73

30. Mendillo ML, Santagata S, Koeva M, Bell GW, Hu R, Tamimi RM, Fraenkel E, Ince TA, Whitesell L, Lindquist S (2012) HSF1 drives a transcriptional program distinct from heat shock to support highly malignant human cancers. Cell 150(3):549_ 562. https://doi.org/10.1016/j.cell.2012.06.031

31. Tosi F, Sartori F, Guarini P, Olivieri O, Martinelli N (2014) Delta-5 and delta- 6 desaturases: crucial enzymes in polyunsaturated fatty acid-related pathways with pleiotropic influences in health and disease. Adv Exp Med Biol 824:61-81. https://doi. org/10.1007/978-3-319-07320-0_7

32. Obukowicz MG, Welsch DJ, Salsgiver WJ, Martin-Berger CL, Chinn KS, Duffin KL, Raz A, Needleman P (1998) Novel, selective delta6 or delta5 fatty acid desaturase inhibitors as antiinflammatory agents in mice. J Pharmacol Exp Ther 287(1):157-166

33. Dolgin E (2019) XPO1 inhibitor approved for multiple myeloma. Cancer Discov. https://doi.org/10.1158/2159-8290.cd-nb2019-085

34. Gounder MM, Zer A, Tap WD, Salah S, Dickson MA, Gupta AA, Keohan ML, Loong HH, D'Angelo SP, Baker S, Condy M, Nyquist-Schultz K, Tanner L, Erinjeri JP, Jasmine FH, Friedlander S, Carlson R, Unger TJ, Saint-Martin JR, Rashal T, Ellis J, Kauffman M, Shacham S, Schwartz GK, Abdul Razak AR (2016) Phase IB Study of Selinexor, a first-in-class inhibitor of nuclear export, in patients with advanced refractory bone or soft tissue sarcoma. J Clin Oncol 34(26):3166-3174. https://doi.org/10.1200/ jco.2016.67.6346

35. Rouquette J, Choesmel V, Gleizes PE (2005) Nuclear export and cytoplasmic processing of precursors to the 40S ribosomal subunits in mammalian cells. EMBO J 24(16):2862-2872. https://doi. org/10.1038/sj.emboj.7600752

36. Thomas F, Kutay U (2003) Biogenesis and nuclear export of ribosomal subunits in higher eukaryotes depend on the CRM1 export pathway. J Cell Sci 116(Pt 12):2409-2419. https://doi. org/10.1242/jcs.00464

37. Zhu ZC, Liu JW, Yang C, Zhao M, Xiong ZQ (2019) XPO1 inhibitor KPT-330 synergizes with Bcl-xL inhibitor to induce cancer cell apoptosis by perturbing rRNA processing and $\mathrm{Mcl}-1$ protein synthesis. Cell Death Dis 10(6):395. https://doi.org/10.1038/ s41419-019-1627-9

38. Roeten MSF, Cloos J, Jansen G (2018) Positioning of proteasome inhibitors in therapy of solid malignancies. Cancer Chemother Pharmacol 81(2):227-243. https://doi.org/10.1007/s0028 0-017-3489-0

39. Menendez JA, Lupu R (2007) Fatty acid synthase and the lipogenic phenotype in cancer pathogenesis. Nat Rev Cancer 7(10):763-777. https://doi.org/10.1038/nrc2222

40. Olsen AM, Eisenberg BL, Kuemmerle NB, Flanagan AJ, Morganelli PM, Lombardo PS, Swinnen JV, Kinlaw WB (2010) Fatty acid synthesis is a therapeutic target in human liposarcoma. Int $\mathrm{J}$ Oncol 36(5):1309-1314. https://doi.org/10.3892/ijo_00000616

41. Santos CR, Schulze A (2012) Lipid metabolism in cancer. FEBS J 279(15):2610-2623. https://doi.org/10.111 1/j.1742-4658.2012.08644.x

42. Little JL, Wheeler FB, Koumenis C, Kridel SJ (2008) Disruption of crosstalk between the fatty acid synthesis and proteasome pathways enhances unfolded protein response signaling and cell death. Mol Cancer Ther 7(12):3816-3824. https://doi.org/10.1158/15357163.mct-08-0558 
43. Pei XY, Dai Y, Grant S (2004) Synergistic induction of oxidative injury and apoptosis in human multiple myeloma cells by the proteasome inhibitor bortezomib and histone deacetylase inhibitors. Clin Cancer Res 10(11):3839-3852. https://doi.org/10.1158/10780432.ccr-03-0561

44. Schelman WR, Traynor AM, Holen KD, Kolesar JM, Attia S, Hoang T, Eickhoff J, Jiang Z, Alberti D, Marnocha R, Reid JM, Ames MM, McGovern RM, Espinoza-Delgado I, Wright JJ, Wilding G, Bailey HH (2013) A phase I study of vorinostat in combination with bortezomib in patients with advanced malignancies. Invest New Drugs 31(6):1539-1546. https://doi.org/10.1007/ s10637-013-0029-6

45. Flores C, Fouquet G, Moura IC, Maciel TT, Hermine O (2019) Lessons to learn from low-dose cyclosporin-A: a new approach for unexpected clinical applications. Front Immunol 10:588. https ://doi.org/10.3389/fimmu.2019.00588

46. Isshiki Y, Tanaka H, Suzuki Y, Yoshida Y (2017) Cyclosporine is a potential curative treatment option for advanced thymoma. Exp Hematol Oncol 6:13. https://doi.org/10.1186/s40164-017-0073-6
47. Ross HJ, Cho J, Osann K, Wong SF, Ramsinghani N, Williams J, Downey-Hurtado N, Slater LM (1997) Phase I/II trial of low dose cyclosporin A with EP for advanced non-small cell lung cancer. Lung Cancer 18(2):189-198

48. Anaya J (2016) OncoLnc: linking TCGA survival data to mRNAs, miRNAs, and lncRNAs. PeerJ Comput Sci. https://doi. org/10.7717/peerj-cs.67

49. Di Veroli GY, Fornari C, Wang D, Mollard S, Bramhall JL, Richards FM, Jodrell DI (2016) Combenefit: an interactive platform for the analysis and visualization of drug combinations. Bioinformatics 32(18):2866-2868. https://doi.org/10.1093/bioinformatics/ btw230

Publisher's Note Springer Nature remains neutral with regard to jurisdictional claims in published maps and institutional affiliations. 